\title{
A produção literária e o impacto da aproximação dos estudantes de Medicina
}

\section{durante a sua formação: revisão integrativa}

The literary production and the impact of approach of Medical students during their training:

\author{
integrative review
}

Producción literaria y aproximación y el impacto de estudiantes de Medicina durante su

formación: revisión integrativa

Recebido: 26/12/2021 | Revisado: 01/01/2022 | Aceito: 04/01/2022 | Publicado: 05/01/2022

\author{
Raimundo José Arruda Bastos \\ ORCID: https://orcid.org/0000-0002-5912-7175 \\ Centro Universitário Christus, Brasil \\ E-mail: arrudabastos@gmail.com \\ Marcos Miranda Vasconcelos \\ ORCID: https://orcid.org/0000-0002-1906-6734 \\ Centro Universitário Christus, Brasil \\ E-mail: marcosmirandavasconcelos@hotmail.com \\ Mariana Keli Ferreira dos Santos Hansen \\ ORCID: https://orcid.org/0000-0002-9679-7389 \\ Centro Universitário Christus, Brasil \\ E-mail:mkfs.mariana@gmail.com \\ Deborah Pedrosa Moreira \\ ORCID: https://orcid.org/0000-0003-4313-2479 \\ Centro Universitário Christus, Brasil \\ E-mail: deborah.moreira@unichristus.edu.br
}

\begin{abstract}
Resumo
Em um contexto de diálogo entre a literatura e a medicina, está lidando com a condição humana e suas características, temos o médico como coadjuvante importante, priorizando o ouvir, o propor e guiar as condutas direcionadas ao paciente; este como ator principal no cenário do atendimento humanizado. Com isso, este estudo compila as informações disponíveis nas produções científicas sobre o impacto da aproximação dos estudantes de medicina com a produção literária durante a sua formação. Revisão Integrativa da literatura com busca realizada nas bibliotecas virtuais BVS, SciELO e PubMed, com oito artigos analisados. Estes foram divididos em três eixos: a) mudança de comportamento; b) sensibilidade e questões éticas e c) pensamento crítico, comunicação e diálogo. Ensinar a arte na medicina vai além da capacitação técnico-científica: é preciso preparar, cada vez mais, o futuro médico para lidar com os dilemas, os conflitos e a pluralidade de opiniões da área da saúde e medicina.
\end{abstract}

Palavras-chave: Medicina na literatura; Educação médica; Estudantes de medicina; Medicina; Literatura.

\begin{abstract}
In a context of dialogue between literature and medicine, the latter dealing with the human condition and its characteristics, we have the physician as an important assistant, prioritizing listening, proposing, and guiding the conduct directed to the patient. This is the main actor in the scenario of humanized care. Thus, this study compiles the information available in scientific productions about the impact of the approach of medical students to literary production during their training. Integrative literature review with a search carried out in the virtual libraries BVS, SciELO, and PubMed, with eight articles analyzed. These were divided into three axes: a) behavioral change, b) sensitivity and ethical issues, and c) critical thinking, communication, and dialogue. Teaching the art of medicine goes beyond technical-scientific training: it is necessary to increasingly prepare future physicians to deal with the dilemmas, conflicts, and plurality of opinions in the health field and medicine.
\end{abstract}

Keywords: Medicine in literature; Medical education; Medical students; Medicine; Literature.

\section{Resumen}

En un contexto de diálogo entre literatura y medicina, que trata sobre la condición humana y sus características, tenemos al médico como un asistente importante, priorizando la escucha, proponiendo y orientando las conductas dirigidas al paciente; éste como actor principal en el escenario del cuidado humanizado. Así, este estudio recopila la información disponible en producciones científicas sobre el acercamiento de los estudiantes de medicina a la producción literária y el impacto durante su formación. Revisión de literatura integradora con búsqueda realizada en 
las bibliotecas virtuales BVS, SciELO y PubMed, con ocho artículos analizados. Estos se dividieron en tres ejes: a) cambio de comportamiento; b) sensibilidad y cuestiones éticas yc) pensamiento crítico, comunicación y diálogo. La enseñanza de las artes en la medicina va más allá de la formación técnico-científica: es cada vez más necesario preparar al futuro médico para afrontar los dilemas, los conflictos y la pluralidad de opiniones en el ámbito de la salud y medicina.

Palabras clave: Medicina en la literatura; Educación médica; Estudiantes de medicina; Medicina; Literatura.

\section{Introdução}

Desde os antepassados, medicina e literatura sempre partilharam um território em comum. Ambas lidam com a condição humana, a dor, a doença, a morte, bem como a figura do médico enquanto sujeito ativo capaz de ouvir, propor e guiar as condutas ao doente. Essa importante relação tem sido tema de muitas e valiosas obras literárias, em que vários escritores demonstram uma sensibilidade especial para melhor entender a relação médico-paciente, o que pode ser muito útil para estudantes de medicina (Scliar, 2004).

Partindo desse princípio, a literatura, por intermédio do estudo da linguagem escrita ou falada, é um subsídio para que o estudante de medicina estimule sua criatividade, amplie sua imaginação, aprimore seu pensamento crítico e trabalhe na construção de um vocabulário flexível e mutável de acordo com as diversas classes sociais. Esses atributos, como um todo, permitem que o futuro profissional possa melhor ouvir e compreender a história contada pelo paciente, ajudando-o a entender o que ele expressa, muitas vezes, de forma confusa ou segmentada.

Assim, entender que a literatura e a medicina possuem importante relação é fundamental. Ambas lidam com a palavra. No caso da medicina, a palavra é um instrumento terapêutico, no caso da literatura, um instrumento de criação estética, em que interessantes paralelos podem ser estabelecidos entre esses diferentes usos da palavra (Scliar, 2004).

Desse modo, a inter-relação entre medicina e literatura é um dos aspectos principais das chamadas Humanidades Médicas, haja vista que a atual medicina aparada com o auxílio de intensa tecnologia, necessita, essencialmente, de um humanismo que, dificilmente, será encontrado com tanta abundância quanto na literatura. Assim, não é por acaso que diversas universidades, em todo o mundo, estão investindo em disciplinas que ensinem literatura e história da medicina.

Nesta revisão integrativa, compilamos as informações disponíveis nas produções científicas sobre o impacto da aproximação dos estudantes de medicina com a produção literária durante a sua formação.

\section{Metodologia}

Trata-se de uma revisão integrativa da literatura (Souza, et al., 2010). A busca, a escolha e a análise deram-se pela concordância com a pergunta norteadora: “Como a aproximação dos estudantes de medicina com a produção literária impacta durante a sua formação?”.

A busca pelos artigos foi realizada na Biblioteca Virtual de Saúde (BVS), na base de dados PubMed e Scientific Electronic Library Online (SciELO). Na primeira busca, foram incluídas as bases de dados Literatura Latino-Americana en Ciencias de la Salud (LILACS) e Índice Bibliográfico Español en Ciencias de la Salud (IBECS). No PubMed, foram utilizados os filtros "free full text", pesquisa realizada com "humans" e artigos disponibilizados na base de dados National Library of Medicine (MEDLINE).

Entre os critérios de inclusão, foram artigos disponíveis na íntegra, em que a busca foi realizada sem recorte de tempo, e publicados nos idiomas português, espanhol e inglês. Os descritores utilizados foram "Medicina na literatura", "Educação médica", "Estudantes de medicina", "Medicina" e "Literatura" juntamente com o operador booleano "AND”, e seus descritores correspondentes em inglês: "Medicine in literature", "Education, medical", "Students, medical", "Literature" e "Medical”, estes foram consultados no Descritores em Ciências da Saúde (DeCS) e no Medical Subject Heading (MeSH), respectivamente. 
Foram excluídas as publicações que continham somente os resumos disponíveis, duplicados, anais e editoriais. Os artigos incluídos dialogam com a abordagem na produção literária por parte dos discentes de medicina. A coleta ocorreu durante os meses de outubro e novembro de 2020 e foi analisada entre pares.

Anteriormente à leitura, na íntegra dos artigos selecionados, seguiram a leitura do título, constando temática concordante com a pergunta norteadora, e, quando confirmado o assunto, o artigo foi selecionado para a análise e para a aplicação no instrumento de coleta do Programa de Habilidades em Leitura Crítica (Critical Appraisal Skills Programme Casp). Ele organiza os dados com base em dez itens e propõe uma nota para o artigo que estiver entre $6-10$ pontos, pois é classificado com boa qualidade metodológica e viés reduzido, enquanto, 0 - 5 pontos, é considerado com viés aumentado.

Entretanto, para a realização deste estudo, foi priorizada a correlação da temática entre os artigos analisados e a pergunta norteadora. Para a aplicação no instrumento, restou uma amostra de 8 artigos, distribuídos com nota no Casp que variam de 3 a 10 pontos, especificados no quadro dois. Os dados foram organizados em quadros em que constam pontos relevantes sobre a temática deste artigo.

\section{Resultados}

Foram analisados oito estudos (Figura 1) e encontrados três eixos temáticos. No primeiro quadro, são apresentados os resultados por meio das buscas de acordo com as bases de dados. 
Figura 1 - Fluxograma da distribuição dos artigos após aplicação do instrumento Casp.

QUESTÃO NORTEADORA

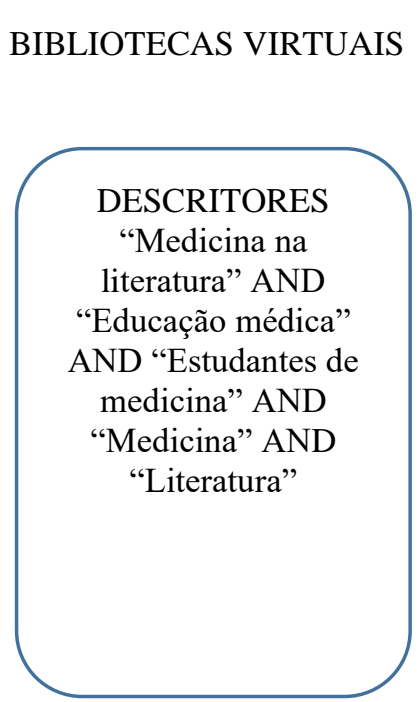

PRÉ-SELECIONADOS

EXCLUÍDOS

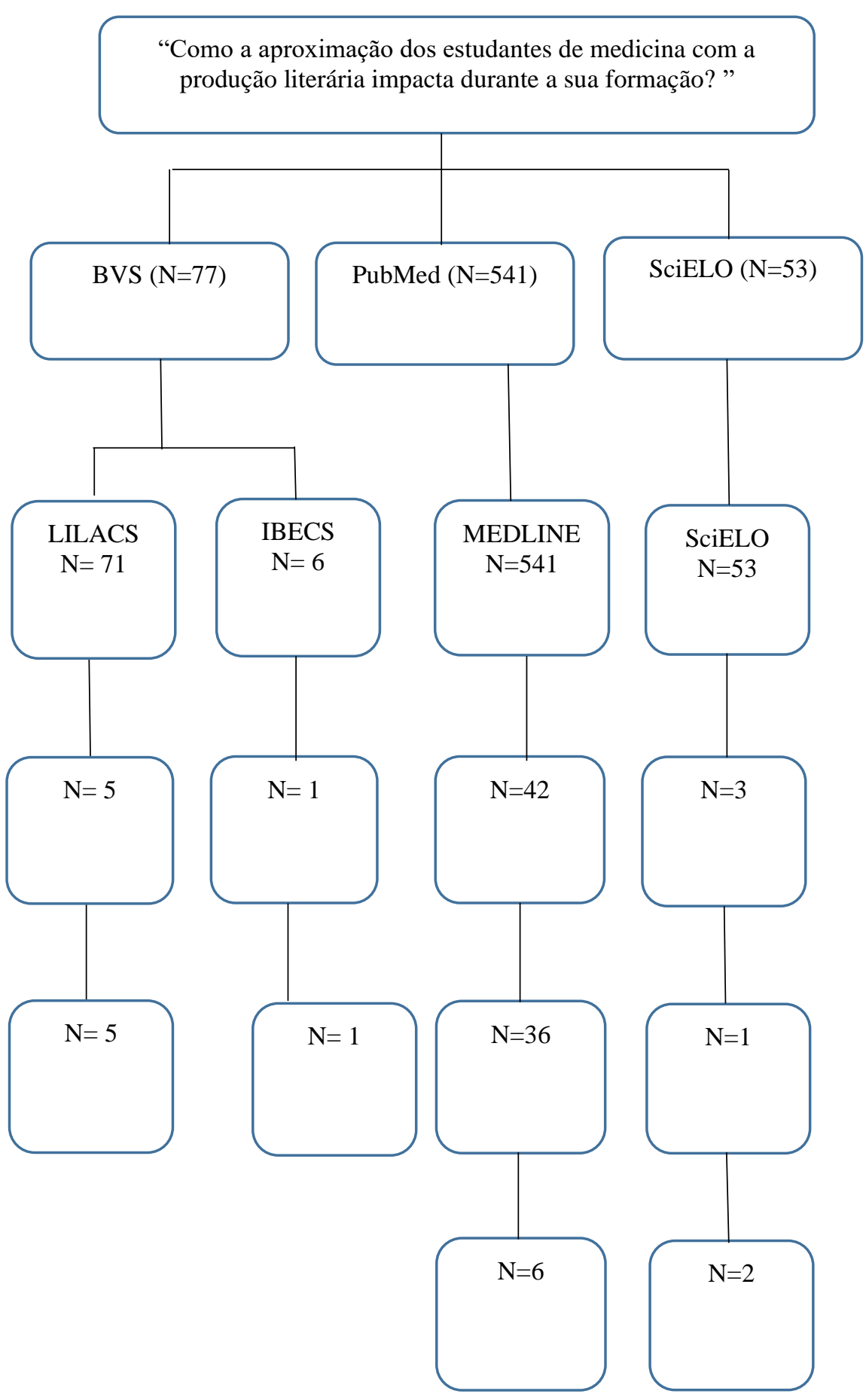

Fonte: Elaboração própria (2021).

Em relação aos tipos de periódicos, cinco foram publicados em revista com enfoque em Medicina e Educação, dois publicados em Vida, Ciência e Educação e um foi publicado em Jornal de Ética e Saúde, sendo a ênfase pautada na descrição do processo de aprendizagem e ensino da área de medicina.

Quando ao local das produções científicas, duas têm origem brasileira, duas são americanas, uma italiana, indiana, coreana e catariano. Acerca do intervalo cronológico dos títulos incluídos, foram publicados entre os anos 2011 a 2019. O Quadro 1 apresenta a caracterização dos artigos segundo título, autores, base de dados e periódico, origem, delineamento da pesquisa, nota do instrumento Casp e ano de publicação. 
Quadro 1 - Distribuição dos artigos segundo título, autor, base de dados e periódico, país de origem, delineamento da pesquisa, pontuação Casp e ano de publicação.

\begin{tabular}{|c|c|c|c|c|c|c|c|}
\hline $\mathbf{N}$ & Título do Artigo & Autores & $\begin{array}{l}\text { Base de dados e } \\
\text { Periódico }\end{array}$ & Origem & $\begin{array}{c}\text { Delineamento da } \\
\text { Pesquisa }\end{array}$ & Casp & Ano \\
\hline 01 & \begin{tabular}{|c|} 
Scientific Growth and \\
Identity Development \\
during a \\
Postbaccalaureate \\
Program: results from a \\
multisite qualitative study
\end{tabular} & Remich et al. & \begin{tabular}{|c|} 
MEDLINE / Cbe-- \\
Life Sciences \\
Education
\end{tabular} & EUA & Estudo longitudinal & $10 / 10$ & 2016 \\
\hline 02 & $\begin{array}{l}\text { Developing the Inner } \\
\text { Scientist: book club } \\
\text { participation and the } \\
\text { nature of science. }\end{array}$ & Griffar et al. & \begin{tabular}{|c|} 
MEDLINE/ Cbe-- \\
Life Sciences \\
Education
\end{tabular} & Catar & Quantitativo, longitudinal & $9 / 9$ & 2013 \\
\hline 03 & $\begin{array}{c}\text { Medicine and literature: a } \\
\text { section in a medical } \\
\text { university library }\end{array}$ & Garlaschelli R. & \begin{tabular}{|c|} 
MEDLINE/ \\
Health Info Libr J.
\end{tabular} & Itália & $\begin{array}{c}\text { Experimental } \\
\text { Longitudinal (2007/ } \\
\text { 2010). } \\
\end{array}$ & $6 / 10$ & 2011 \\
\hline 04 & $\begin{array}{l}\text { Medical themes in a } \\
\text { literature classroom: An } \\
\text { alternate perspective on } \\
\text { Medical Humanities } \\
\text { pedagogy in India }\end{array}$ & $\begin{array}{l}\text { Prabhu, } \\
\text { Gayathri. }\end{array}$ & $\begin{array}{c}\text { MEDLINE/ Indian } \\
\text { Journal of Medical } \\
\text { Ethics }\end{array}$ & Índia & Qualitativo, narrativo & $3 / 10$ & 2018 \\
\hline 05 & $\begin{array}{l}\text { Avaliação do curso de } \\
\text { pensamento crítico para } \\
\text { estudantes de medicina } \\
\text { usando literatura e } \\
\text { cinema }\end{array}$ & Do-Hwa, Kim. & $\begin{array}{l}\text { MEDLINE/ } \\
\text { Korean } \\
\text { J Med Educ. }\end{array}$ & Coreia & $\begin{array}{l}\text { Experimental e } \\
\text { Observacional }\end{array}$ & $9 / 10$ & 2019 \\
\hline 06 & $\begin{array}{c}\text { Students' perceptions of } \\
\text { the impact a creative arts } \\
\text { journal has on their } \\
\text { medical education. }\end{array}$ & Rodriguez et al. & \begin{tabular}{|c|} 
MEDLINE/ Farm \\
Med.
\end{tabular} & EUA & Quantitativo & $7 / 10$ & 2013 \\
\hline 07 & \begin{tabular}{|c|} 
Literatura como \\
Estratégia para Reflexões \\
sobre Humanismo e Ética \\
no Curso Médico: um \\
Estudo Qualitativo
\end{tabular} & Balbi et al. & $\begin{array}{l}\text { LILACS/ Rev. } \\
\text { bras. educ. méd }\end{array}$ & Brasil & $\begin{array}{l}\text { Estudo descritivo de } \\
\text { análise qualitativa }\end{array}$ & $10 / 10$ & 2017 \\
\hline 08 & \begin{tabular}{|c|} 
As Artes na Educação \\
Médica: Revisão \\
Sistemática da Literatura
\end{tabular} & Mairot, et al. & $\begin{array}{l}\text { LILACS/ Rev. } \\
\text { bras. educ. méd }\end{array}$ & Brasil & $\begin{array}{c}\text { Revisão Sistemática da } \\
\text { literatura }\end{array}$ & $10 / 10$ & 2019 \\
\hline
\end{tabular}

Fonte: Elaboração própria (2021).

Entre os artigos selecionados para leitura completa, as principais temáticas encontradas se entrelaçavam com os aspectos comportamentais, éticos e pensamento crítico. Assim, as exposições dos dados foram distribuídas considerando seus resultados e conclusão (Quadro 2).

Quadro 2 - Distribuição dos artigos incluídos segundo resultados e conclusão.

\begin{tabular}{|c|c|c|}
\hline $\mathbf{N}$ & Resultados & Conclusão \\
\hline 01 & $\begin{array}{l}\text { Este estudo atual revela como os participantes mudam durante o } \\
\text { Programa de Educação em Pesquisa de Pós-bacharelado (PREP), os } \\
\text { elementos do programa que facilitam a mudança e como a identidade } \\
\text { de um estudante de graduação e futuro cientista se desenvolve. }\end{array}$ & $\begin{array}{l}\text { O PREP permitiu que os participantes desenvolvessem } \\
\text { suas identidades como alunos de pós-graduação e } \\
\text { antecipassem ser vistos por outros como bastante } \\
\text { preparados para o treinamento de doutorado. }\end{array}$ \\
\hline 02 & $\begin{array}{l}\text { Os alunos que participaram do clube do livro tinham um desempenho } \\
\text { nas Ciências da Natureza }(\mathrm{CN}) \text { ligeiramente melhor no final do ano, } \\
\text { mas também no início, sugerindo que o clube do livro possa ter atraído } \\
\text { em vez de produzir alunos com desempenho CN superior. } \\
\text { É de notar que foi possível detectar uma melhoria na compreensão das } \\
\mathrm{CN} \text {, uma vez que existem poucos relatos de crescimento da CN na } \\
\text { literatura em que a CN não fosse um tópico explícito de instrução. }\end{array}$ & $\begin{array}{l}\text { Os questionários aplicados demonstraram que os alunos, } \\
\text { ao participarem no grupo do livro com leituras de livros } \\
\text { de ficção e não ficção com abordagem e temática nas } \\
\text { ciências biológicas, melhoraram o seu desempenho nas } \\
\text { disciplinas CN. }\end{array}$ \\
\hline 03 & $\begin{array}{l}\text { Uma iniciativa de criar uma seção de literatura na biblioteca de } \\
\text { medicina em uma universidade de Milão onde se prioriza sair do } \\
\text { ensino tradicional, tentando proporcionar uma variedade de produções } \\
\text { que possam ser interligadas com o ensino-aprendizagem na medicina e } \\
\text { tem a possibilidade de atrair novos usuários. }\end{array}$ & $\begin{array}{l}\text { Uma livraria pode atuar estimulando os estudantes a } \\
\text { agregar novos interesses na literatura, e tudo isso pode } \\
\text { contribuir, positivamente, para o treinamento de } \\
\text { estudantes da área de medicina. }\end{array}$ \\
\hline
\end{tabular}




\begin{tabular}{|c|c|c|}
\hline 04 & $\begin{array}{l}\text { Chamar a atenção para as narrativas, bem como desenvolver as } \\
\text { habilidades de reflexão pessoal e engajamento, em que a literatura } \\
\text { transfere uma sensibilidade, olhar holístico, informações éticas que } \\
\text { podem agregar valores ao ensino aprendizagem dos estudantes de } \\
\text { medicina indianos. }\end{array}$ & $\begin{array}{l}\text { As humanidades médicas são estudos bem atuais na } \\
\text { Índia. Ainda devemos construir uma comunidade de } \\
\text { acadêmicos especializados na área ou desenvolver uma } \\
\text { pedagogia coesa, e é provavelmente por esse meio que } \\
\text { precisamos começar. Simultaneamente, as instituições } \\
\text { médicas podem convidar professores visitantes (se não } \\
\text { criarem novos cargos) de humanidades médicas para } \\
\text { ensinar não apenas módulos ou workshops, mas um } \\
\text { curso sério de quatro créditos que é avaliado e faz parte } \\
\text { do histórico escolar do aluno. Sendo necessário } \\
\text { acomodar os estudos literários no currículo médico para } \\
\text { treinar os alunos a chamar a atenção para as narrativas, } \\
\text { bem como desenvolver as habilidades de reflexão } \\
\text { pessoal e engajamento. }\end{array}$ \\
\hline 05 & $\begin{array}{l}\text { Dado que a capacidade de pensamento crítico pode ser considerada como } \\
\text { um dos resultados pretendidos da educação em ciências sociais e } \\
\text { humanas, este estudo explorou a eficácia de um curso para promover o } \\
\text { pensamento crítico em um currículo pré-médico usando literatura e } \\
\text { cinema. Contando com a participação de estudantes no curso de } \\
\text { pensamento crítico para pré-médicos, foram realizados encontros a cada } \\
\text { três semanas para discutir e apresentar seus pontos de vista sobre o } \\
\text { material utilizado e também a escrita de uma redação crítica com a } \\
\text { temática vista. Em média, os alunos valorizaram } 78,6 \% \text { do total de } \\
\text { materiais atribuídos. Os alunos indicaram que as discussões em grupo e } \\
\text { os comentários narrativos dos facilitadores foram os que mais } \\
\text { contribuíram para o desenvolvimento do pensamento crítico. Os alunos } \\
\text { que tiveram pontuações de ensaio crítico maiores ou iguais à mediana } \\
\text { demonstraram uma melhoria significativa nas pontuações de disposição } \\
\text { de pensamento crítico. }\end{array}$ & $\begin{array}{l}\text { Neste estudo mostrou que um curso em um currículo } \\
\text { pré-médico para promover o pensamento crítico usando } \\
\text { literatura e cinema pode ser bem aceito. Contribui para o } \\
\text { aumento no volume de leitura, influencia o pensamento } \\
\text { crítico dos alunos, bem como sua percepção em relação } \\
\text { à leitura. Com base em nessas descobertas, os autores } \\
\text { recomendam aos educadores médicos que considerem a } \\
\text { experiência anterior de leitura dos alunos e usem } \\
\text { atividades de aprendizagem complementares para um } \\
\text { uso mais eficaz da literatura e dos filmes. }\end{array}$ \\
\hline 06 & $\begin{array}{l}\text { Faculdade de Medicina da Universidade do Estado da Flórida } \\
\text { (FSUCOM) criou o HEAL: Humanism Evolving through Arts and } \\
\text { Literature, um jornal, em que apresenta um criativo trabalho de } \\
\text { estudantes, faculdades e residentes, incluindo artigos, poesia, fotografia e } \\
\text { visual arte e assim comunicar com respeito e apreciação pelos outros. } \\
\text { Cerca de } 81 \% \text { dos entrevistados gostaram de ler HEAL. Muitos } \\
\text { entrevistados concordaram que o HEAL promove o cuidado centrado no } \\
\text { paciente }(55,9 \%) \text { e pode prevenir o Burnout }(61,8 \%) \text {. Sessenta e quatro } \\
\text { por cento achavam que o HEAL os ajudava a entender seus colegas e } \\
\text { colegas de classe, o que colaborou para uma relação de trabalho em } \\
\text { equipe melhor. A maioria mencionou a importância de autorreflexão e } \\
\text { narrativa/comunicação, que são cruciais ao diálogo empático com } \\
\text { pacientes. }\end{array}$ & $\begin{array}{l}\text { Este estudo mostrou que um jornal criativo realizado por } \\
\text { estudantes e leitores da comunidade acadêmica geral, } \\
\text { traz benefícios para estudantes de medicina, pois } \\
\text { ocorreram melhora nas relações interpessoais, } \\
\text { compreensão das limitações dos colegas, } \\
\text { reconhecimento de como a comunicação é um fator } \\
\text { forte ao cuidado efetivo e empatia. }\end{array}$ \\
\hline 07 & $\begin{array}{l}\text { Com base na leitura da obra de Saramago, os alunos responderam a } \\
\text { uma avaliação processual desse componente. Segundo o conteúdo das } \\
\text { respostas dos alunos, foram obtidos quatro temas: observação do } \\
\text { mundo e do exercício profissional pelo estudante de Medicina; } \\
\text { humanização na prática médica diante da invisibilidade social; prática } \\
\text { médica tecnocêntrica e humanização; percepção do estudante de } \\
\text { medicina sobre a importância da literatura em sua formação. A } \\
\text { diversidade, a riqueza e a verticalidade das respostas apresentadas } \\
\text { permitem concluir que a leitura do livro Ensaio sobre a Cegueira } \\
\text { contribuiu, de maneira positiva, para a aprendizagem dos princípios } \\
\text { éticos e bioéticos (beneficência, não maleficência, autonomia e } \\
\text { justiça), tendo acrescentado à formação pessoal e profissional dos } \\
\text { estudantes. }\end{array}$ & $\begin{array}{l}\text { A literatura contribui, de maneira positiva, para a } \\
\text { aprendizagem dos princípios éticos e bioéticos, na obra } \\
\text { de José Saramago, Ensaio sobre a Cegueira, com a } \\
\text { diversidade de temáticas, propiciou aos estudantes } \\
\text { capacidade interpretativa, reflexiva e crítica. }\end{array}$ \\
\hline 08 & $\begin{array}{l}\text { As competências educacionais sensíveis às artes relatadas nos estudos } \\
\text { avaliados foram: habilidades de observação diagnóstica, trabalho em } \\
\text { equipe, reflexão e argumentação; facilidade do aprendizado cognitivo; } \\
\text { aspectos humanísticos da medicina (empatia/relação médico- } \\
\text { paciente); profissionalismo. Alguns estudos afirmam que as } \\
\text { intervenções baseadas em artes são eficazes na alteração de atitudes; } \\
\text { entretanto, não definiram como esse sucesso foi medido. Nenhum } \\
\text { estudo considera os efeitos sobre o comportamento. As evidências } \\
\text { para o uso de intervenções baseadas em artes para promover } \\
\text { habilidades de observação diagnóstica mostraram ser mais fortes. No } \\
\text { entanto, seu efeito em outras habilidades clínicas não foi estudado. }\end{array}$ & $\begin{array}{l}\text { A arte pode ser uma estratégia facilitadora do } \\
\text { aprendizado, uma vez que auxilia o estudante a lidar } \\
\text { com a complexidade do ser humano e da saúde humana. } \\
\text { Esse conhecimento mais amplo sobre a saúde e a doença } \\
\text { pode levar à melhoria da relação médico-paciente na } \\
\text { prática clínica; e as intervenções baseadas em artes, dos } \\
\text { estudos selecionados, abordam aspectos humanísticos da } \\
\text { medicina. }\end{array}$ \\
\hline
\end{tabular}




\section{Discussão}

Após análise dos textos, surgiram três eixos temáticos: a) mudança de comportamento; b) sensibilidade e questões éticas e c) pensamento crítico, comunicação e diálogo.

\section{Mudança de comportamento}

A observação detalhada dos estudos mostrou o desenvolvimento de aspectos humanísticos da medicina, como a observação diagnóstica, o aprendizado cognitivo, a habilidade de reflexão e argumentação, o profissionalismo e a capacidade de trabalhar em equipe. A natureza metafórica e representacional das artes bem como sua subjetividade são capazes de desafiar o pensamento concreto ou literal e servem, assim, para legitimar as experiências e emoções pessoais dos alunos em lidar com uma variedade de tópicos (Mariot, et al., 2019; Haidet, et al., 2016). Essas características da arte podem fornecer subsídios para repensar a educação médica e a prática clínica, tendo em vista que pode ser uma ferramenta que amplia a capacidade de compreensão e intervenção na realidade, em uma perspectiva autônoma, democrática e responsável.

É válido ressaltar, também, o desenvolvimento do pensamento crítico sobre os problemas a serem encontrados em carreira futura. Isso se deve, entre outros fatores, à capacidade das artes visuais em melhorar as habilidades de observação, descrição, interpretação e resposta dos estudantes de Medicina em relação aos aspectos subjetivos do cuidado médico (Mariot, et al., 2019; Elder, et al., 2006; Tapajós, 2003). Como exemplo, os estudos sugerem que relacionar as pinturas com o diagnóstico físico tornou-se uma maneira de melhorar a acurácia diagnóstica dos estudantes, haja vista que as artes visuais desencadeiam sentimentos e transmitem consciência de valores e sentimentos pessoais (Mariot, et al., 2019; Naghshineh, et al., 2008). À vista disso, a arte possibilita que o aluno aprenda a aceitar e a considerar interpretações alternativas, além de estimular o trabalho em equipe, essencial na prática profissional. Outro fator refere-se ao fato de a arte promover habilidades específicas e psicomotoras úteis à profissão, como a visão espacial e a capacidade de pensar em três dimensões, atributos que podem desenvolver o aprendizado sobre aspectos da anatomia clínica e topografia humana (Mariot, et al., 2019; McMenamin, 2008).

O uso da literatura (leitura de poesia, paródia e notícias) pode melhorar a empatia à medida que aprimora a relação médico-paciente, haja vista que pode ser utilizada para auxiliar o aluno a lidar com a complexidade do adoecer, percepção dos sentimentos, atitudes e comportamentos, identificação das relações interpessoais perceptivas e expressivas e interpretação da fala do paciente durante a prática clínica. Estes fatores, como um todo, demonstram que a análise dos poemas estimulou a reflexão crítica sobre valores humanísticos da prática profissional, dessa forma, pode-se validar a utilização da arte como estratégia educacional.

Diante disso, apesar de promover modificações positivas nos estudantes, devem-se destacar o desconforto e a ansiedade apresentados por alguns estudantes ao participarem de atividades baseadas em arte. Deve-se, também, levar em consideração que alguns estudantes não veem a relevância da utilização da arte no currículo. Além disso, a natureza subjetiva das artes e a ausência de instrumentos padronizados para avaliação da sua contribuição na formação de futuros médicos propõem a necessidade de estudos de metodologias mistas (qualitativos e quantitativos) com características longitudinais para evidenciar o verdadeiro efeito das artes como estratégia educacional no currículo médico.

Portanto, os estudos sugerem que os estudantes, no geral, referem satisfação com as estratégias baseadas em arte no currículo médico. Portanto, muitos são os benefícios da arte como estratégia educacional capaz de proporcionar desenvolvimento pessoal e profissional, além de representar uma fonte de percepção das experiências dos pacientes e do contexto social, cultural e histórico das práticas médicas. 


\section{Sensibilidade e questões éticas}

A medicina contemporânea vivencia um momento de mudanças, além disso, promove o tecnicismo com avanços em diagnóstico e tratamento de doenças; ela reconhece a importância de modificar a relação médico-paciente, abandonando o paternalismo que abrange a autonomia do doente e passando a valorizar, cada vez mais, a formação ética do profissional, preconizada pelo Código de Ética Médica (Balbi, 2017; Silva, 2013).

À vista disso, ensinar a arte na medicina vai além da capacitação técnico-científica: é preciso preparar, cada vez mais, o futuro médico para lidar com os dilemas, os conflitos e a pluralidade de opiniões da área da saúde (Balbi, et al., 2017; Silva, 2013). A literatura constitui mais um recurso didático de metodologia ativa, uma vez que proporciona reflexões sobre si mesmo, sobre valores, relações humanas, questões político-sociais, além de desenvolver as habilidades clínicas do estudante, como as capacidades de observação, interpretação, imaginação clínica e até mesmo a fluência linguística (Balbi, et al., 2017; Nery Filho, 2013).

A avaliação dos estudos sugere que o uso da arte pode colaborar para uma reflexão sobre os princípios éticos e bioéticos, como autonomia, justiça, beneficência e não maleficência, haja vista as inúmeras obras literárias que abordam, metaforicamente, temas que repercutem a relação médico-paciente na presença de doenças e fazem um convite ao autoconhecimento. Além disso, a arte demanda do aluno a habilidade de distinguir as diferentes formas de visão (olhar, enxergar e reparar) aplicadas no contexto social, seja como cidadão, seja no âmbito médico.

Assunção (2008 apud Balbi, et al., 2017) cita que há uma preocupação para formar um profissional de saúde mais humanizado e que este anseio é compartilhado por diferentes instituições na realidade educacional brasileira. É sabido que as escolas médicas têm um grande desafio: formar um profissional que promove, recupera e reabilita a saúde de forma integral, tendo senso de responsabilidade social e de cidadania. No entanto, elas ainda não têm conseguido cumprir, com louvor, o seu papel, principalmente no eixo ético-humanístico, o que destaca a importância de substituir a racionalidade técnica pela de cunho crítico e emancipatório.

Estudo realizado no curso de Medicina da Universidade Federal do Rio Grande do Norte (UFRN) destaca a perspectiva de ter uma educação ética e humana transdisciplinar, durante toda a sua formação. Nessa instituição, o desafio está sendo idealizado em duas direções: a busca da aproximação e envolvimento dos docentes e áreas do saber envolvidas na formação médica; e a necessidade de utilizar métodos pedagógicos ativos que façam o estudante ser protagonista do seu aprendizado, para que possa refletir e desenvolver um raciocínio moral crítico e complexo relacionado a questões reais da vida (Amorim \& Araújo, 2013), o que aponta para a importância de uma matriz desenhada para atingir as competências humanas e sociais por meio de estratégias aplicadas no decorrer da formação.

Por isso, espera-se que o médico utilize a tecnologia de maneira consciente e considere as subjetividades do paciente sem esquecer a sua dimensão espiritual/religiosa que exerce influência positiva na qualidade de vida do paciente e na sua sobrevida em situações de cuidados paliativos.

\section{Pensamento crítico, comunicação e diálogo}

O desenvolvimento de muitas habilidades médicas essenciais para o estudante, como a boa comunicação com o paciente, a transmissão de uma má notícia e o reconhecimento das emoções transferidas pelo doente, pode ser aprimorado pelo advento de obras literárias. O HEAL é um exemplo disso, uma ferramenta literária que significa Humanismo em evolução por meio das artes e da literatura.

Reunindo escrita e arte de uma variedade de fontes, o HEAL é uma plataforma onde estudantes de medicina compartilham seu crescimento e desenvolvimento, professores e funcionários compartilham seus conhecimentos adquiridos com a experiência e membros da comunidade expressam como a saúde e a cura impactaram suas vidas (Rodriguez, et al., 
2013). O HEAL se esforça para preencher a lacuna crescente entre os pacientes e seus provedores, enquanto espera produzir uma saída criativa significativa para aqueles que participam da publicação de suas edições digitais trimestrais e periódico impresso anual.

Assim, cursos curriculares, obrigatórios ou eletivos, são oferecidos nas escolas médicas, alguns com experiência de anos e convenientemente institucionalizados, outros ainda em caráter pioneiro. Literatura e teatro, poesia, cinema, ópera e artes compõem o mosaico de recursos que os educadores, em atitude verdadeiramente humanista, tomam emprestados das humanidades na tentativa de auxiliar na construção da identidade do futuro médico (Biasco, et al., 2005).

Experiências exitosas como as descritas no estudo de Villela e Costa (2020) com o uso da arte com alunos da medicina oportunizam o desenvolvimento de habilidades de comunicação e despertam valores humanísticos, essenciais para sua formação, contribuindo para uma formação diferenciada e sensibilizada com os aspectos sociais.

Almeida e Portella (2021) retratam que o grande desafio da Universidade é mediar um ensino significativo, reflexivo, que promova a emancipação intelectual dos estudantes de medicina por meio do pensamento crítico, considerando esta a base para o raciocínio clínico e a tomada de decisões conscientes.

Dessa forma, é possível inferir que os recursos humanísticos na educação médica possuem amplo espectro da condição humana. O auxílio de obras literárias é um exemplo claro disso. Cada vez, com maior frequência, surgem iniciativas vinculadas às humanidades e às artes, na tentativa - urgente, e ao mesmo tempo, paciente e continuada - de conduzir o estudante de hoje, médico de amanhã, ao caminho da reflexão sobre a riqueza da dimensão humana.

\section{Conclusão}

O manuscrito buscou fazer uma revisão integrativa sobre o impacto da aproximação dos estudantes de medicina com a produção literária durante a sua formação. De forma geral, as pesquisas indicam que essa interface traz benefícios para o médico em formação, colaborando, ativa e positivamente, nos aspectos humanísticos.

As evidências encontradas elucidam os seguintes aspectos: pensamento crítico; envolvimento; diálogo e comunicação; postura ética e profissional; mudança de comportamento e sensibilidade, como desfecho diante da produção literária que colaboraram neste processo.

O estudo forneceu dados bibliográficos que reforçam a ênfase na aproximação da produção literária no processo de formação do médico, auxiliando no desenvolvimento de profissionais comprometidos, humanizados, éticos e integrados à equipe de saúde.

Sugere-se que futuros trabalhos de revisão e de pesquisa de campo sejam desenvolvidos para fortalecer o incentivo à produção e a aproximação literária entre estudantes de medicina.

\section{Agradecimentos}

Aos alunos do curso de Medicina do Centro Universitário Christus (Unichristus) e ao Setor de Atendimento Linguístico da Unichristus.

\section{Referências}

Almeida, A. L. \& Portella, D. L. (2021) A avaliação do pensamento crítico: uma abordagem a estudantes de medicina brasileiros. Research, Society and Development, 10(12) e122101220203, http://dx.doi.org/10.33448/rsd-v10i12.20203

Amorim, K. P. C. \& Araújo, E. M. (2013) Formação ética e humana no curso de medicina da UFRN: uma análise crítica. Revista Brasileira de Educação Médica 37(1), 138-148. <https://doi.org/10.1590/S0100-55022013000100020>. https://doi.org/10.1590/S0100-55022013000100020.

Amorim, M. P. \& Silva, I. (2014). Instrumento de avaliação do pensamento crítico em estudantes e profissionais de saúde. Psicologia, Saúde e Doenças, 15(1):122-137. https://www.redalyc.org/articulo.oa?id=36231157011

Assunção, L. F., Melo, G. C. M. P. \& Maciel, D. T. (2008). Relação Médico-paciente Permeando o Currículo na Ótica do Estudante. Revista Brasileira de 
Research, Society and Development, v. 11, n. 1, e22611125139, 2022

(CC BY 4.0) | ISSN 2525-3409 | DOI: http://dx.doi.org/10.33448/rsd-v11i1.25139

Educação Médica 32 (3), 383-89. http://www.scielo.br/pdf/rbem/v32n3/v32n3a13.pdf

Balbi, L., Lins, L. \& Menezes, M. S. (2017). A Literatura como Estratégia para Reflexões sobre Humanismo e Ética no Curso Médico: um Estudo Qualitativo. Revista Brasileira de Educação Médica., 41(1), 152-161. https://doi.org/10.1590/1981-52712015v41n1rb20160049.

Biasco, P. G., Gallian, D. M. C., Roncoletta, A. F. T. \& Moreto, G. (2005). Cinema para o estudante de medicina: um recurso afetivo/efetivo na educação humanística. Revista Brasileira de Educação Médica. 29(2):119-128 https://doi.org/10.1590/1981-5271v29.2-018

Elder, N., Tobias, B., Lucero-Criswell, A. \& Goldenhar, L. (2006) The art of observation: impact of a family medicine and art museum partnership on student education. Fam Med;38(6):393-98.

Faria, M. V. E. \& Junior da Costa, C. (2020). Humanizando a Medicina por meio da Comunicação \& Arte. Revista Extensão \& Cidadania, 8(14), 108-118. https://doi.org/10.22481/recuesb.v8i14.7822

Garlaschelli, R. (2011). Medicine and literature: a section in a medical university library. Health Information \& Libraries Journal. 28(2):137-142. $10.1111 / \mathrm{j} .1471-1842.2011 .00931$

Griffard, P. B., Mosleh, T. \& Kubba, S. (2013). Developing the Inner Scientist: book club participation and the nature of science. Cbe-Life Sciences Education, [S.L.], 12(1):80-91. American Society for Cell Biology (ASCB). http://dx.doi.org/10.1187/cbe.12-02-0020.

Han, H, \& Lopp, L. (2013) Writing and reading in the electronic health record: an entirely new world. Med Educ Online. 5(18):1-7. 10.3402/meo.v18i0.18634

Kim, D. H. (2019). Evaluation of critical thinking course for premedical students using literature and film. Korean J Med Educ. 31(1):19-28, 10.3946/kjme.2019.115.

Mairot, L. T. S., Costa, B. B. G., Heringer, T. P. M., Borges, R. C. \& Moura, E. P. (2019). As Artes na Educação Médica: Revisão Sistemática da Literatura. Rev. bras. educ. med. 43(4)54-64, http://dx.doi.org/10.1590/1981-52712015v43n4rb20180146.

Naghshineh, S., Hafler, J. P., Miller, A. R., Blanco, M. A., Lipsitz, S. R., Dubroff, R. P. et al. (2008) Formal art observation training improves medical students visual diagnostic skills. J Gen Intern Med; 23(7):991-97.

Prabhu, G. (2018) Medical themes in a literature classroom: An alternate perspective on Medical Humanities pedagogy in India. Indian Journal of Medical Ethics, 4(1) 35-46.

Remich, R., Naffziger-Hirsch, M. E., Gazley, J. L., \& Mcgee, R. (2016). Scientific Growth and Identity Development during a Postbaccalaureate Program: results from a multisite qualitative study. Cbe-Life Sciences Education. 15(3):15-25. American Society for Cell Biology (ASCB). http://dx.doi.org/10.1187/cbe.16-01-0035.

Rodriguez, J. E., Welch, T. J., Saunders, C. \& Edwards, J. C. (2013). Students' perceptions of the impact a creative arts journal has on their medical education. Fam Med. 45(8):569-571.

Scliar, M. (2004) Medicina e Literatura. Faculdade de Medicina da UFMG.

Souza, M. T., Silva, M. D. \& Carvalho, R. (2010). Revisão Integrativa: O que é e como fazer. Einstein. 8(1 Pt 1):102-106.

Tapajós R. (2003) HIV/AIDS in the visual arts: applying discipline-based art education (DBAE) to medical humanities. Med Educ;37(6):563-70. 